\title{
Revisiting Nonoperative Treatment of Lateral Compression Pelvic Fractures. Analysis of Rehabilitation and Radiologic Outcomes in a Historical Cohort Using Today's AO Stability Criteria.
}

\section{Claudio Rojas}

Hospital of the Worker of Santiago: Hospital del Trabajador de Santiago

ERNESTO EWERTZ ( EFETMT@GMAIL.COM )

Clínica Dávila: Clinica Davila https://orcid.org/0000-0002-3968-3502

Jose Miguel Hormazabal

Hospital of the Worker of Santiago: Hospital del Trabajador de Santiago

\section{Research article}

Keywords: pelvic fracture, LC-I, orthopedic treatment, conservative treatment

Posted Date: November 1st, 2021

DOI: https://doi.org/10.21203/rs.3.rs-995468/v1

License: (c) (i) This work is licensed under a Creative Commons Attribution 4.0 International License.

Read Full License 


\section{Abstract}

Background: Type I lateral compression pelvic fractures (LC-I) have historically been treated conservatively. Inferior outcomes in a distinctive subset of these injuries has been reported, therefore their management has shifted towards surgery. Revisiting historical series of LC-I allows us to determine whether non-operative management of these unstable patterns result in poorer outcomes. The objective was to evaluate the differences in the rehabilitation progress, fracture consolidation and displacement in non-operatively treated LC-I fractures that would be considered unstable using today's AO criteria.

Methods: We conducted a retrospective review of conservatively treated LC-I injuries in a single level I trauma center, between June 2010 and June 2014. Patients were distributed in Stable (Group A) and unstable (Group B) groups according to 2018 AO classification. Time to walk independently (TWI), time to return to work (TRW), fracture consolidation and displacement were analyzed.

Results: 34 patients, mean aged $45.5 \pm 14.5$ years, were included. Mean TWI in groups A and B were 71.2 \pm 31.9 and $105.9 \pm 50.9$ days $(p=0.027$ ). Mean TRW was $106 \pm 51.3$ and $157 \pm 84$ days in Groups $A$ and $B$ respectively $(p=0.038)$. A difference in mean TWI and TRW of 34.7 and 51.3 days between groups was observed. No significant differences in fracture consolidation or displacement were observed.

Conclusion: Unstable fractures presented significantly longer TWI and TRW. The revised AO classification contributes in the identification of fracture patterns that correlate with prolonged rehabilitation in which additional treatment strategies might be considered.

\section{Introduction:}

Lateral compression (LC) fractures are among the most common pelvic ring injuries, representing between 57 to $63 \%$ of these injuries [1,2]. The initial studies of Tile and Young and Burgess, grouped these fractures according to their primary mechanism of injury and direction of instability [3]. These injuries represent a spectrum of continuous damage to pelvic structures ranging from stable to rotationally and vertically unstable fractures $[4,5]$. Type I lateral compression fractures (LC-I) have historically been managed nonoperatively due to the theoretic integrity of ligaments that provide structural stability $[6,7]$.

In the last decade this assertion has been questioned. Bruce et al. in a series of 117 patients reported fracture displacement in as many as $40 \%$ of LC-I injuries with complete posterior sacral disruption [8]. Sagi et al. reported that $35 \%$ of OTA B2 fractures stressed under anesthesia were unstable enough to require operative management [9]. Tosoudinis et al. reported significant improvements in length of hospital stay, time to independent pain-free mobilization, post-manipulation pain levels and opioid requirements in surgically treated LC-I patients [10]. In light of this evidence a revised pelvic fracture classification from the $\mathrm{AO}$ group was recently published, suggesting surgical management according to the severity of the posterior arch injury. [11]. 
Currently the evaluation of how non-operatively treated patients with unstable fractures perform is difficult due to a more aggressive approach towards surgery. Revisiting the historical series of conservatively treated LC-I fractures allows us to determine whether the re-defined unstable patterns present poorer outcomes.

The objective of this study is to evaluate the differences in the rehabilitation progress, fracture consolidation and displacement in non operatively treated LC-I fractures that would be considered unstable per today's AO stability criteria.

\section{Materials And Methods:}

Institutional board review approval was obtained and the requirement for written informed consent was waived in relation to this study. We conducted a retrospective cohort study of a historical series of non operatively treated LC-I patients between June 2010 and June 2014 in a single level I trauma - workers insurance center.

We revised all patients admitted with pelvic fracture diagnosis. Conservatively treated LC-I fractures were included. Exclusion criteria were defined as the presence of associated injuries that interfered with immediate standing and walking (severe traumatic brain injuries, upper extremity injuries that precluded walking aids, lower extremity injuries that required unloading) and incomplete radiological studies in the digital imaging software. (AGFA Xero Viewer 8.1.2 system). Three independent investigators including the senior author analyzed the radiological images.

Fractures were grouped according to the 2018 AO classification system in stable (61 B1.1) - Group A and unstable fractures (61 B2.1) - Group B-. (12)

Patients were followed in office by trained pelvic trauma surgeons. The rehabilitation progress was assessed by analyzing the time to walk independently without walking aids (TWI) and time to return to work (TRW) extracted from digital clinical chart registries. Consolidation of posterior sacral fracture and displacement $(>10 \mathrm{~mm})$ in any direction were determined comparing pelvic AP - Inlet - Outlet views and CT scans at admission and at 6 months follow up, and analyzed as a binary variable.

Statistical analysis was performed using Stata Statistical Software (Release 13. College Station, TX: StataCorp LP). Normal distribution of the population was evaluated using the Shapiro-Wilk test. Differences between groups were evaluated using t-student for continuous and Fisher's exact test for categorical variables. A p value for statistical significance was set at $<0.05$. Age, TWI and TWR values are presented in means and standard deviation (SD). Institutional board review approval was obtained,

\section{Results:}

Between June 2010 and June 2014, a total of 116 patients with pelvic ring fractures were admitted to our institution. 66 patients met the inclusion criteria. Twenty-seven patients presented associated injuries that 
precluded immediate weight bearing and in 5 patients the use of walking aids was not registered. Thirtyfour patients were selected for final analysis.

Seventeen women and 17 male patients, mean aged $45.5 \pm 14.5$ years were included. Fifteen patients were considered stable and assigned to Group $A$ and 19 patients were considered unstable and assigned to group B. Patients in group A and group B presented similar age ( $49.2 \pm 16.09$ years vs $43 \pm 12,8 p=$ 0.89 ) and gender distribution ( $M: F=7: 8$ vs $M: F=11: 8 ; p=0.7)$

Complete description of anterior and posterior arch fracture characteristics is presented in Table 1. In Group A, 14 patients presented unilateral pubic rami fractures, 8 of them were multifragmentary. No comminuted posterior arch fractures were observed in this group.

In Group B, 12 patients presented unilateral rami fractures; 3 of them were contralateral to the posterior pelvic injury and 7 had bilateral pubic rami fractures. Multifragmentary anterior arch fractures were observed in 7 patients. In posterior arch injuries, 14 simple and 5 multifragmentary sacral fractures were observed.

Table 1

Fracture radiologic characteristics and 2018 AO classification. 


\begin{tabular}{|c|c|c|c|}
\hline & & Group A & Group B \\
\hline $\mathrm{N}^{0}$ patients & & 15 & 19 \\
\hline \multicolumn{4}{|c|}{ Anterior arch injury characteristics } \\
\hline & Simple Unilateral & 6 & 6 \\
\hline & Simple Bilateral & 0 & 4 \\
\hline & Multifragmentary Unilateral & 8 & 6 \\
\hline & Multifragmentary Bilateral & 1 & 3 \\
\hline \multicolumn{4}{|c|}{ Posterior arch injury characteristics } \\
\hline & Incomplete fracture & 15 & 0 \\
\hline & Complete simple fracture & 0 & 14 \\
\hline & Complete Multifragmentary fracture & 0 & 5 \\
\hline \multicolumn{4}{|c|}{ AO 2018 classification } \\
\hline & 61B1.1 & 15 & - \\
\hline & 61B2.1 & - & 19 \\
\hline \multicolumn{4}{|l|}{ Qualifications } \\
\hline & a Ipsi or unilateral pubic rami fractures & 12 & 9 \\
\hline & b Bilateral pubic rami fractures & 0 & 7 \\
\hline & c Contralateral pubic rami fractures & 0 & 3 \\
\hline & e Parasymphyseal fracture & 3 & 0 \\
\hline
\end{tabular}

Three patients presented delayed consolidation and 1 patient presented significant displacement at 6 month follow up, all belonging to the unstable fracture group (group B). No significant differences in consolidation or displacement were observed between groups. Detailed clinical and radiological values are presented in Table 2 .

Table 2

Clinical and radiological variables 


\begin{tabular}{|c|c|c|c|}
\hline & Group A & Group B & $p$ value \\
\hline \multicolumn{4}{|l|}{ Clinical evolution $†$} \\
\hline \multirow[t]{2}{*}{ TWI (days) } & $71,2[53-88]$ & $105,94[81-130]$ & $0.027 *$ \\
\hline & 106,2 [83-129] & $157,5[109-160]$ & $0.038^{*}$ \\
\hline \multicolumn{4}{|l|}{ TRW (days) } \\
\hline \multicolumn{4}{|c|}{ Radiological evolution $\ddagger$} \\
\hline No Displacement & 15 & 18 & 0.7 \\
\hline Displacement & 0 & 1 & \\
\hline Consolidation & 15 & 16 & 0.25 \\
\hline Non union & 0 & 3 & \\
\hline \multicolumn{4}{|c|}{$\begin{array}{l}\text { † Values: mean, range }, \ddagger \text { Values: number of patients } \\
\text { * statistically significant }\end{array}$} \\
\hline
\end{tabular}

The mean TWI in group $A$ and $B$ was $71.2 \pm 31.9$ and $105.9 \pm 50.9$ days respectively $(p=0.027)$. The mean TRW $106 \pm 51.3$ vs $157 \pm 84$ days $(p=0.038)$ respectively. Group A presented a decrease in mean TWI of 34.7 days and in mean TRW of 51.3 days when compared with group B. (Table 2).

\section{Discussion:}

Despite significant advances in trauma surgery in the last few decades, the understanding of biomechanics and prediction of pelvic fracture stability remains controversial $[8,12]$. Even though Young \& Burgess classification aids to comprehend the injury mechanisms and anticipate associated lesions, it is insufficient to accurately predict how these fractures behave under physiological loads. Previously, the AO based their classification on the direction in which instability of the pelvic ring was presumed; B2.1 and B2.2 fractures were considered rotationally unstable with maintained vertical stability; albeit also failing to accurately predict future displacement [13]. Given the evidence available following the initial description of Pennal et al. and through the first decade of XXI century, LC-I fractures used to be managed nonoperatively [14]. However, new evidence gave rise to question whether some of them would benefit from surgical fixation.

The wide spectrum of fracture severity, recoil phenomena, displacement and differences in clinical outcomes makes these a particularly difficult group of fractures to evaluate $[8,9,15-17]$. On the other hand, prediction of the dynamic behavior of these injuries with current static imaging methods, adds to the complexity of decision making. Dynamic stress testing under anesthesia is useful, but impractical to apply in all patients. 
Displacement has been associated with poorer outcomes in pelvic fractures and the time needed to progress in physical rehabilitation has important physical and psychological consequences for these patients[18-22]. In 2018 the AO classification system incorporates the differentiation of stable and unstable lateral compression fractures primarily based on the severity of the posterior sacral fracture [11].

In this study we evaluated the rehabilitation milestones of TWI and TRW; consolidation and fracture displacement of non-operatively treated LC fractures, that under today's scope would be considered unstable.

An objective assessment of displacement in pelvic fractures is difficult. The complex three-dimensional anatomy and the impossibility of getting standardized comparable imaging in the trauma setting make the evaluation unreliable.[23] In this study we conducted a subjective radiologic analysis relying on the ability of trained pelvic trauma surgeons to identify fracture displacement and consolidation. Only the unstable fracture patterns (group B) presented fracture displacement and delays in consolidation, though no significant differences between groups were observed. On the other hand, stable and unstable fractures presented significant differences in TWI and TRW. This suggests that the 2018 AO criteria helps to identify patients in whom a non operative approach results in prolonged rehabilitation periods, though whether the surgical treatment of these unstable fractures improves outcomes remains unclear [19,2429].

This study has many limitations. The retrospective nature of the study doesn't allow for functional scores or patient reported outcomes measure scores to be applied. The sample is small and composed entirely of workers entitled to compensation benefits which limits the external validation of the results.

This study adds to the growing evidence demonstrating variable outcomes in the highly heterogeneous LC-I fracture group. The revised 2018 AO classification system contributes in the identification of unstable fracture patterns that correlate with longer rehabilitation and work absentee times in which additional treatment strategies might be considered. Further studies should be conducted to determine the functional impact of surgery in these patients.

\section{Abbreviations}

$L C=$ lateral compression fracture

LC-I = Type I lateral compression fracture

$\mathrm{TWI}=$ time to walk independently without walking aids

$T R W=$ time to return to work

\section{Declarations}




\section{Ethics approval:}

This study was approved by the local ethics committee

\section{Consent for publication:}

N/A

\section{Availability of data and material (data transparency):}

N/A

\section{Conflicts of interest/Competing interests:}

Authors declare no conflict of interest nor competing interest in relation to this study

\section{Funding:}

no funding was received in relation to this study.

\section{Authors contribution:}

CR was involved in the study design, data acquisition, data analysis and interpretation and drafting.

$\mathrm{JH}$ was involved in the study design, data analysis and interpretation and drafting.

EE was involved in the study design, data analysis and interpretation and drafting.

\section{Acknowledgements:}

$\mathrm{N} / \mathrm{A}$

\section{References}

1. Manson T, O'Toole R V., Whitney A, Duggan B, Sciadini M, Nascone J. Young-burgess classification of pelvic ring fractures: Does it predict mortality, transfusion requirements, and non-orthopaedic injuries? J Orthop Trauma 2010;24:603-8.

2. J W Young, A R Burgess, R J Brumback, A Poka. Pelvic fractures: Value of plain radiography in early assessment and management. Radiology 1986; 160: 445-51 
3. Tile M. Pelvic ring fractures: Should they be fixed? J Bone Joint Surg Br. 1988; 70: 1-12.

4. Alton TB, Gee AO. Classifications in brief: Young and Burgess classification of pelvic ring injuries. Clin Orthop Relat Res 2014; 472: 2338-42.

5. Burgess AR, Eastridge BJ, Young JWR, Ellison TS, Ellison PS, Poka A, et al. Pelvic ring disruptions: Effective classification system and treatment protocols. J Trauma - 1990; 30: 848-56.

6. Gordon RO, Mears DC. Lateral compression injury of the pelvis. A case report. J Bone Joint Surg Am. 1991; 73:1399-1401.

7. Miranda MA, Riemer BL, Butterfield SL, Burke CJ 3rd. Pelvic ring injuries. A long term functional outcome study. Clin Orthop Relat Res. 1996; 329:152-9.

8. Bruce B, Reilly M, Sims S. OTA highlight paper: Predicting future displacement of nonoperatively managed lateral compression sacral fractures: Can it be done? J Orthop Trauma 2011; 25: 523-7.

9. Sagi HC, Coniglione FM, Stanford JH. Examination under anesthetic for occult pelvic ring instability. J Orthop Trauma 2011; 25: 529-36.

10. Tosounidis T, Kanakaris N, Nikolaou V, Tan B, Giannoudis P V. Assessment of Lateral Compression type 1 pelvic ring injuries by intraoperative manipulation: Which fracture pattern is unstable? Int Orthop 2012; 36: 2553-8.

11. Meinberg EG, Agel J, Roberts CS, Karam MD, Kellam JF. Fracture and Dislocation Classification Compendium 2018. vol. 32. 2018.

12. Khoury A, Kreder $H$, Skrinskas $T$, Hardisty M, Tile M, Whyne CM. Lateral compression fracture of the pelvis represents a heterogeneous group of complex 3D patterns of displacement. Injury 2008; 39:893-902.

13. Fracture and dislocation compendium. Orthopaedic Trauma Association Committee for Coding and Classification. J Orthop Trauma 1996;10 Suppl 1.

14. Tile M, Pennal GF. Pelvic Disruption. Clin Orthop Relat Res 1980; 151: 56-64

15. Lefaivre KA, Padalecki JR, Starr AJ. What constitutes a young and burgess lateral compression-I (OTA 61-B2) pelvic ring disruption? A description of computed tomography-based fracture anatomy and associated injuries. J Orthop Trauma 2009; 23:16-21.

16. Weaver MJ, Bruinsma W, Toney E, Dafford E, Vrahas MS. What are the patterns of injury and displacement seen in lateral compression pelvic fractures? Trauma. Clin Orthop Relat Res 2012;470:2104-10.

17. Gardner MJ, Krieg JC, Simpson TS, Bottlang M. Displacement after simulated pelvic ring injuries: A cadaveric model of recoil. J Trauma 2010; 68:159-65.

18. Gerbershagen HJ, Dagtekin O, Isenberg J, Martens N, Özgür E, Krep H, et al. Chronic pain and disability after pelvic and acetabular fractures-assessment with the mainz pain staging system. $\mathrm{J}$ Trauma 2010; 69:128-36.

19. Suzuki T, Shindo M, Soma K, Minehara H, Nakamura K, Uchino M, et al. Long-term functional outcome after unstable pelvic ring fracture. J Trauma 2007; 63:884-8. 
20. Kokubo Y, Oki H, Sugita D, Takeno K, Miyazaki T, Negoro K, et al. Functional outcome of patients with unstable pelvic ring fracture: Comparison of short and long term prognostic factors. J Orthop Surg $2017 ; 25: 1-6$.

21. Quality of Life After Pelvic Trauma. Lippincott's Bone Joint Newsl 2008;14:89-90.

22. Metze M, Tiemann AH, Josten C. Male sexual dysfunction after pelvic fracture. J Trauma 2007; 63: 394-401.

23. Nystrom LM, McKinley TO, Marsh JL. Accuracy in radiographic assessment of pelvic ring fracture deformity: Analysis of current methods. J Orthop Trauma 2013; 27:708-15.

24. Hagen J, Castillo R, Dubina A, Gaski G, Manson TT, O'Toole R V. Does Surgical Stabilization of Lateral Compression-type Pelvic Ring Fractures Decrease Patients' Pain, Reduce Narcotic Use, and Improve Mobilization? Clin Orthop Relat Res 2016; 474:1422-9.

25. Banierink H, Reininga IHF, Heineman E, Wendt KW, ten Duis K, IJpma FFA. Long-term physical functioning and quality of life after pelvic ring injuries. Arch Orthop Trauma Surg 2019; 139:122533.

26. Hernefalk B, Eriksson N, Larsson S, Borg T. Patient-reported Outcome in Surgically Treated Pelvic Ring Injuries at 5 Years Post-surgery [published online ahead of print, 2019 Sep 19]. Scand J Surg. 2019;1457496919877583. doi:10.1177/1457496919877583

27. Gaski GE, Manson TT, Castillo RC, Slobogean GP, O'Toole R V. Nonoperative treatment of intermediate severity lateral compression type 1 pelvic ring injuries with minimally displaced complete sacral fracture. J Orthop Trauma 2014; 28:674-80.

28. Gabbe BJ, Hofstee DJ, Esser M, Bucknill A, Russ MK, Cameron PA, et al. Functional and return to work outcomes following major trauma involving severe pelvic ring fracture. ANZ J Surg 2015; 85:749-54.

29. Hoffmann MF, Jones CB, Sietsema DL. Persistent impairment after surgically treated lateral compression pelvic injury hip. Clin Orthop Relat Res 2012; 470:2161-72.

\section{Supplementary Files}

This is a list of supplementary files associated with this preprint. Click to download.

- STROBEChecklist.doc 